\title{
Magnetic Properties of Poly (Divinylbenzene, Ethylene Glycol Dimethacrylate and Vinyl Alcohol) Containing Barium Ferrite Nanoparticles
}

\author{
S. GUNES ${ }^{a}$, S.K. AKAY ${ }^{a, *}$ AND A. KARA ${ }^{b}$ \\ ${ }^{a}$ Department of Physics, Faculty of Sciences and Arts, Uludag University, 16059 Bursa, Turkey \\ ${ }^{b}$ Department of Chemistry, Faculty of Sciences and Arts, Uludag University, 16059 Bursa, Turkey \\ Three different kinds of polymer films, poly (divinylbenzene), poly (ethylene glycol dimethacrylate) and poly \\ (vinyl alcohol), containing $M$-type hexagonal barium ferrites (BaFe12O19) were synthesized on glass substrates \\ by using surface polymerization method. The structural properties were characterized by X-ray diffraction and \\ atomic force microscopy. X-ray diffraction patterns show that polymer films have a polycrystalline structure. The \\ magnetic measurement of polymer films were examined at room temperature using vibrating sample magnetometer \\ and magnetic force microscopy, respectively. The magnetic measurements indicate that $\mathrm{P}(\mathrm{VA})-\mathrm{BF}$ films exhibit \\ higher saturation magnetization and coercive field than $\mathrm{P}(\mathrm{EGDMA})-\mathrm{BF}$ and $\mathrm{P}(\mathrm{DVB})-\mathrm{BF}$ films.
}

DOI: 10.12693/APhysPolA.125.538

PACS: 68.37.Rt, 75.75.Fk, 82.35.Np

\section{Introduction}

Various experimental methods, sputtering [1], sol-gel technique [2-4], hydrothermal process $[5,6]$, reverse microemulsion technique [7] have been employed to prepare barium ferrite (BaFe12O19). Barium ferrite that has hexagonal crystal structure is a well known high performance permanent magnetic material and used in production as a disk driver, microwave device [8], and magnetic recording media [9] in recent years.

The new imaging technique, magnetic force microscopy (MFM), allows us to observe magnetic domain structure in thin films and thicker materials. With high resolution properties, MFM is a preferred method than the other techniques [10-12]. In the present work, $M$-type hexagonal barium ferrite (BaFe12O19) nanoparticles doped into various polymers were prepared and their structural properties and especially, magnetic domain patterns were investigated by using magnetic force microscopy.

\section{Experimental procedure}

Materials used in this investigation were described in detail. Ethylene glycol dimethacrylate (EGDMA) was purchased from Merck (Darmstadt, Germany) purified by passing through active alumina and stored at $4{ }^{\circ} \mathrm{C}$ until used. The 2,2'-azobisisobutyronitrile (AIBN) was obtained from Fluka A.G. (Buchs, Switzerland). The poly vinyl alcohol (PVA), divinylbenzene (DVB), barium ferrite (BF) and toluene were supplied from Aldrich Chem. Co. (USA).

\footnotetext{
*corresponding author; e-mail: kakay@uludag.edu.tr
}

In order to prepare $M$-type barium ferrite containing $\mathrm{P}(\mathrm{DVB}), \mathrm{P}$ (EGDMA) and $\mathrm{P}(\mathrm{VA})$ films, surface polymerization technique was used [13]. In this method, each solution, consisting of $1.5 \mathrm{~mL}$ toluene, $0.3 \mathrm{~mL}$ EGDMA, $0.3 \mathrm{~mL}$ DVB, $1.0 \mathrm{~g} \mathrm{VA}, 500 \mathrm{mg}$ AIBN and $1.0 \mathrm{~g}$ BF were used to prepare $\mathrm{P}$ (EGDMA)-BF, $\mathrm{P}(\mathrm{DVB})-\mathrm{BF}$ and $\mathrm{P}(\mathrm{VA})-\mathrm{BF}$ films, respectively. The mixtures were degassed for 30 min by nitrogen purging prior to the addition of the initiator, AIBN. Then the polymerization was conducted for $2 \mathrm{~h}$ at $30^{\circ} \mathrm{C}$ under stirring and nitrogen atmosphere. After $2 \mathrm{~h}$, the solutions were transferred onto glass substrates, cleaned immediately, and the polymerization was continued for 1 day at $80^{\circ} \mathrm{C}$ in an oven. The thickness of the polymer films was approximately $150 \mu \mathrm{m}$.

The structural properties of P(EGDMA)-BF, $\mathrm{P}(\mathrm{DVB})-\mathrm{BF}$ and $\mathrm{P}(\mathrm{VA})-\mathrm{BF}$ films were analyzed by APD 2000 PRO (Italy) X-ray diffraction (XRD) operated at $40 \mathrm{kV}$ and using $\mathrm{Cu} K_{\alpha}$ radiation. Vibrating sample magnetometer (VSM), at room temperature, was used to record hysteresis loops of the films. The topographic and magnetic force microscope (MFM) images were taken using a Multimode Atomic Force Microscope (Nanomagnetics Int., Turkey). The MFM tip is coated with Al. In order to observe magnetic domain patterns, the tip trace the sample surface four times [14]. MFM imaging mode is based on tapping mode. The tip lift-height is $100 \mathrm{~nm}$ and resonant frequency of the tip is $75 \mathrm{kHz}$.

\section{Results and discussion}

Figure 1 presents the XRD patterns of $\mathrm{P}(\mathrm{VA})-\mathrm{BF}$, $\mathrm{P}$ (EGDMA)-BF and P(DVB)-BF films. A step for $2 \theta$ is taken from $15^{\circ}$ to $70^{\circ}$. The individual diffracting planes from the hexagonal structure can be clearly identified and 
labeled. XRD patterns show that polymer films have a very small crystalline size. As can be seen from Fig. 1, $\mathrm{P}$ (VA)-BF film has a diffraction peak separately from other polymer films labeled at $18.92^{\circ}$.

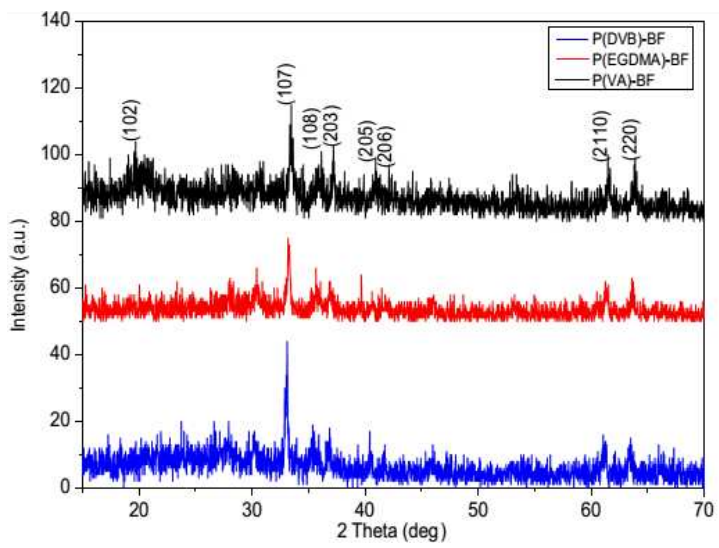

Fig. 1. The XRD patterns of $\mathrm{P}(\mathrm{VA})-\mathrm{BF}, \mathrm{P}(\mathrm{EGDMA})-$ $-\mathrm{BF}$, and $\mathrm{P}(\mathrm{DVB})-\mathrm{BF}$ films.

Magnetic hysteresis loops (M-H) of $\mathrm{P}(\mathrm{VA})-\mathrm{BF}$, $\mathrm{P}$ (EGDMA)-BF and $\mathrm{P}$ (DVB)-BF films were recorded by VSM. It can be observed from Fig. 2 that the saturation magnetization increases from 0.011 to $0.020 \mathrm{emu} / \mathrm{g}$ and coercive field 141 to 197 Oe. The high saturation magnetization and coercive field have been obtained from $\mathrm{P}$ (VA)-BF films. These results show that polyvinyl alcohol has a distinct role on the magnetic properties. The magnetic parameters of the various structures are presented in Table.

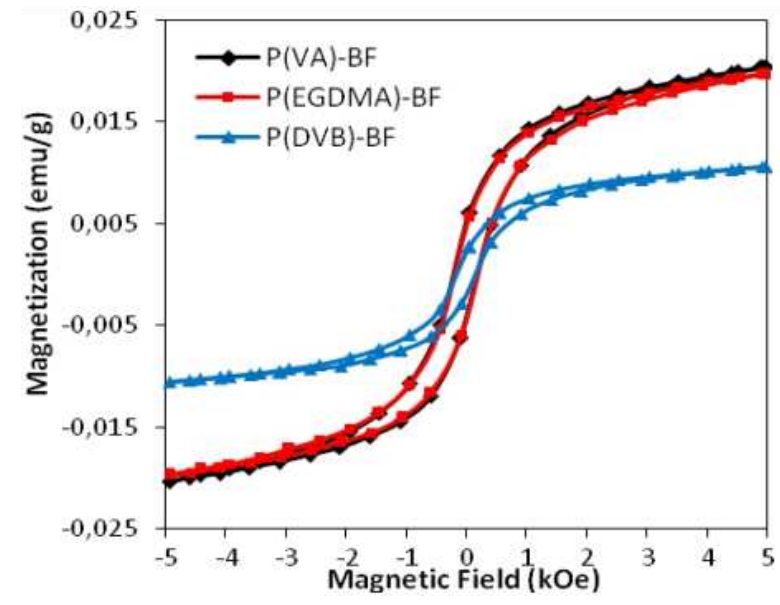

Fig. 2. Magnetic hysteresis loops of $\mathrm{P}(\mathrm{VA})-\mathrm{BF}$, $\mathrm{P}$ (EGDMA)-BF and $\mathrm{P}$ (DVB)-BF films at $300 \mathrm{~K}$.

Figure $3 \mathrm{a}-\mathrm{c}$ shows AFM images of barium ferrite containing polymer films. For AFM analysis, a cantilever endowed with a special coated tip was scanned over a surface of polymer films by using tapping mode to observe topography. The root mean square roughness (rms) of $\mathrm{P}$ (VA)-BF, $\mathrm{P}$ (EGDMA)-BF and $\mathrm{P}$ (DVB)-BF films is measured as $16 \mathrm{~nm}, 240 \mathrm{~nm}$, and $119 \mathrm{~nm}$, respectively.

TABLE

The magnetic parameters of $\mathrm{P}(\mathrm{VA})-\mathrm{BF}, \mathrm{P}$ (EGDMA)-BF and $\mathrm{P}(\mathrm{DVB})-\mathrm{BF}$ films.

\begin{tabular}{c|c|c|c}
\hline \hline & $\mathrm{P}(\mathrm{VA})-\mathrm{BF}$ & $\mathrm{P}(\mathrm{EGDMA})-\mathrm{BF}$ & $\mathrm{P}(\mathrm{DVB})-\mathrm{BF}$ \\
\hline$M_{\mathrm{s}}[\mathrm{emu} / \mathrm{g}]$ & 0.0204 & 0.0197 & 0.0106 \\
$M_{\mathrm{r}}[\mathrm{emu} / \mathrm{g}]$ & 0.0045 & 0.0043 & 0.0019 \\
$H_{\mathrm{c}}[\mathrm{Oe}]$ & 197 & 187 & 141
\end{tabular}

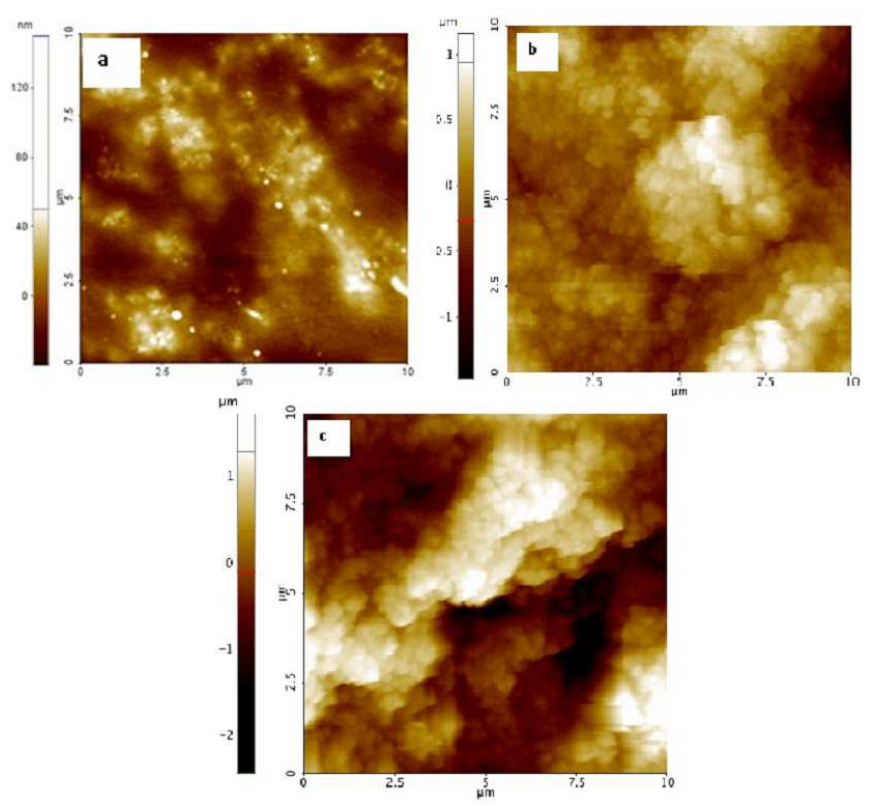

Fig. 3. AFM images of (a) $\mathrm{P}(\mathrm{VA})-\mathrm{BF}$, $\mathrm{P}$ (EGDMA)-BF, and (c) P(DVB)-BF films.

Figure $4 \mathrm{a}$ and $\mathrm{b}$ shows MFM images of $\mathrm{P}(\mathrm{VA})-\mathrm{BF}$ film. As it can be seen from Fig. 4a, P(VA)-BF film shows stripe-like magnetic domain patterns. The bright and dark areas in MFM image represent magnetization direction. The observed domain patterns are property of materials with magnetic anisotropy perpendicular to the sample surface [15].
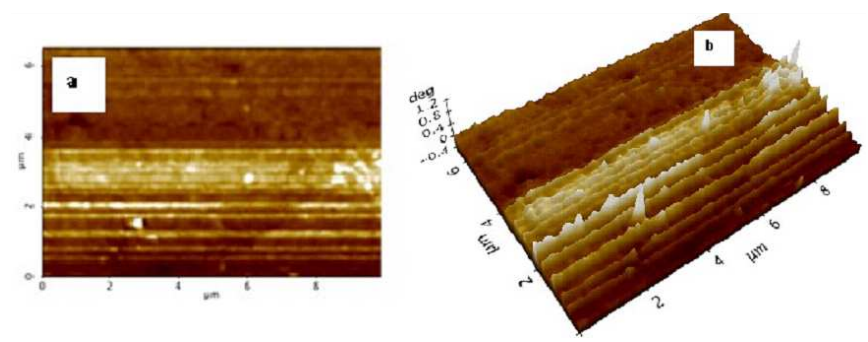

Fig. 4. MFM images (left hand side, 2D, right hand side, 3D) of $\mathrm{P}(\mathrm{VA})-\mathrm{BF}$ films. 


\section{Conclusion}

In this study, various polymer films containing barium ferrite nanoparticles were synthesized. The structural and magnetic properties of the polymer films were investigated by XRD, AFM and MFM. XRD results showed that polymer films have a very small crystalline size. Surface roughness measurements revealed that $\mathrm{P}(\mathrm{VA})-$ -BF film has a smooth surface in comparison with other polymer films. The highest saturation magnetization was obtained from $\mathrm{P}(\mathrm{VA})-\mathrm{BF}$ films. According to the MFM images, the magnetic domain patterns of $\mathrm{P}(\mathrm{VA})-\mathrm{BF}$ film is in the form of stripe-like with opposite magnetization perpendicular to the polymer film surface.

\section{Acknowledgments}

This work was supported by Uludag University, Scientific Research Project Unit Grant No. 2012/14. The authors would like to thank Uludag University for this financial support.

\section{References}

[1] A. Kaewrawang, A. Ghasemi, X. Liu, A. Morisako, Thin Solid Film 518, 7059 (2010).

[2] N.C. Pramanik, T. Fujii, M. Nakanishi, J. Takada, Mater. Lett. 59, 468 (2005).

[3] S.M. Masoudparah, S.A. Seyyed Ebrahimi, J. Magn. Magn. Mater. 324, 2239 (2012).
[4] Z. Durmus, A. Baykal, H. Sozeri, M.S. Toprak, Synt. Reac. In. Met. Org. Nano Met. Chem. 42, 1390 (2012).

[5] S. Ovtar, D. Lisjak, M. Drofenik, J. Am. Ceram. Soc. 94, 3373 (2011).

[6] D. Lisjak, S. Ovtar, J. Phys. Chem. B 117, 1644 (2013).

[7] P. Xu, X. Han, M. Wang, J. Phys. Chem. C 111 , 5866 (2007).

[8] I. Harward, Y. Nie, D. Chen, J. Baptist, J.M. Shaw, E.J. Liskova, S. Visnosky, P. Siroky, M. Lesnak, J. Pistora, Z. Celinski, J. Appl. Phys. 113, 043903 (2013).

[9] L. Li, K. Chen, H. Liu, G. Tong, H. Qian, B. Hao, J. Alloys Comp. 557, 11 (2013).

[10] H. Saito, K. Miyazaki, S. Ishio, J. Magn. Magn. Mater. 240, 73 (2002).

[11] A. Diestel, A. Backen, V. Neu, L. Schultz, S. Fahler, Scr. Mater 67, 423 (2012)

[12] I. Garcia, N. Iturriza, J.J.D. Val, H. Grande, J.A. Pomposo, J. Gonzalez, J. Magn. Magn. Mater. 322, 1822 (2010).

[13] M.A. Ahmetoglu, A. Kara, N. Tekin, S. Beyaz, H. Kockar, Thin Solid Films 520, 2106 (2012).

[14] K. Tanaka, Y. Mori, H. Yamagiwa, S. Abo, F. Wakaya, M. Takai, Mic. Elect. Eng. 84, 1416 (2007).

[15] W. Szmaja, W. Kozlowski, K. Polanski, J. Balcerski, M. Cichomski, J. Grobelny, M. Zielinski, E. Miekos, Mater. Chem. Phys. 132, 1060 (2012). 